\title{
Slipping Through the Cracks? The Impact of Reporting Mental Health Records to the National Firearm Background Check System
}

\author{
Fredrick E. Vars \\ University of Alabama - School of Law, fvars@law.ua.edu \\ Griffin Sims Edwards \\ University of Alabama at Birmingham - Department of Marketing, Industrial Distribution \& Economics, \\ gse@uab.edu
}

Follow this and additional works at: https://scholarship.law.ua.edu/fac_working_papers

\section{Recommended Citation}

Fredrick E. Vars \& Griffin S. Edwards, Slipping Through the Cracks? The Impact of Reporting Mental Health Records to the National Firearm Background Check System, (2018).

Available at: https://scholarship.law.ua.edu/fac_working_papers/88 


\title{
THE UNIVERSITY OF ALABAMA $S C H O O L O F \quad L A W$
}

Slipping Through the Cracks? The Impact of Reporting Mental Health Records to the National Firearm Background Check System

\author{
Fredrick E. Vars \\ Griffin Sims Edwards
}

Working Paper

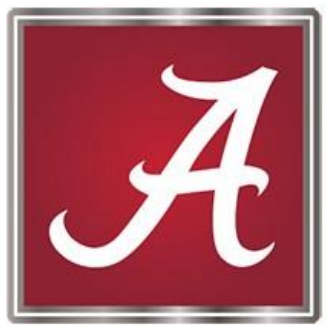

This paper can be downloaded without charge from the Social Science Research Network Electronic Paper Collection: http://ssrn.com/abstract $=3127786$ 


\title{
Slipping Through the Cracks?
}

\section{The Impact of Reporting Mental Health Records to the National Firearm Background}

\author{
Check System
}

Fredrick Vars*

Griffin Edwards

\begin{abstract}
Both sides of the contentious debate over firearm regulation agree that some people with mental illness should be prohibited from purchasing firearms. This consensus exists despite limited empirical support. Such support will be essential to courts deciding the prohibition's constitutionality. We assess the impact on homicide and suicide of states reporting mental health records to the national firearm background check system. Using panel data and a difference-indifferences methodology, we find that upon adding mental health records to the national system, states experienced a 3.3-4.3\% decrease in firearm-related suicides with no evidence of substitution to non-firearm suicides. Our findings suggest that mental health restrictions on gun sales do effectively reduce suicide but not homicide.
\end{abstract}

Topics: Firearms, Mental Health, Suicide, Homicide

\footnotetext{
* School of Law, The University of Alabama, Tuscaloosa, AL; fvars@law.ua.edu Collat School of Business, The University of Alabama at Birmingham, BEC 209B, Birmingham, AL, 35294; gse@uab.edu
} 


\section{Introduction}

The horrific reality in which we currently live is a culture inundated with gun violence.

On an average day, 99 individuals die from a firearm (Edwards, G., E. Nesson, J. Robinson and F. Vars 2017). Mass shootings are becoming such a part of American culture and so commonplace that most of us cannot even remember which one is the "most recent." Nonetheless, gun control remains a touchy, polarizing, and in many circles, taboo topic of discussion. While finding common ground between the two ends of the gun control spectrum has proven historically difficult, virtually everyone favors preventing firearm purchase by individuals who are perceived to be "dangerous" — particularly by those who are mentally ill.

Surveys suggest that even between 80 and $90 \%$ of Republican gun owners favor preventing the mentally ill from purchasing guns (Center, P. R. 2017). Further, based on a belief that the current background check system was too porous, President Obama lobbied to increase the scope of background checks to capture more individuals deemed mentally unfit to purchase a firearm. While the National Rifle Association (NRA) opposed this expansion, the stated rationale was not distaste for background checks but rather that the existing background check system was grossly under-inclusive making. In a remarkable convergence, President Obama similarly argued that "the names of millions of . . . adjudicated mentally incompetent and dangerous people are missing from the background check system," (NRA 2016). Although their policy prescriptions differed, both President Obama and the NRA CEO agreed that the current background check system was far too porous.

While there is a strong general consensus by those of all political and social walks of life in favor of prohibiting firearm purchases by the mentally ill, there is, at best, only indirect evidence to support such a prohibition. Better evidence would help inform judges who must 
decide the constitutional boundaries of the mental health prohibition. Federal law is designed to prevent firearm purchases by several categories of individuals, including certain individuals with mental illness. The burden of reporting those names to the federal system, however, falls primarily on the individual states where those records are kept. Even today, the degree to which individual states comply and report to the federal system is unclear. In the states that do report significant numbers of mental health records to the federal system, we know very little about the effect on firearm-related deaths. Using data from a variety of sources on the actual number of names reported by states, we are able to tease out the effect of firearm background checks on gun-related homicides and suicides.

We find that when states report mental health records to the federal system, they experience a 3.3-4.3\% reduction in firearm-related suicides with no evidence of substitution to non-firearm suicide methods. Conversely, however, we find no evidence of any relationship between mental health reporting and homicides. In essence, filling the mental health gaps in the current background check system is effective in decreasing gun-related suicides but does not affect gun-related homicides.

\section{Background}

Federal law has long prohibited firearm possession by certain categories of "dangerous" people. Since 1968, one such category has been any person "who has been adjudicated as a mental defective or who has been committed to a mental institution.” In 1998, the federal Brady Act set up a prophylactic approach: the National Instant Criminal Background System ("NICS"). All federally licensed gun dealers are now required to conduct a background check before selling a firearm. The potential efficacy of NICS requires that the names of those disqualified from owning a firearm actually be in the federal database, and the presence of those names- 
especially those deemed mentally unfit to own a firearm - hinges on the cooperation of each individual state to report the names of people disqualified from purchasing firearms.

NICS participation has varied widely — especially as it relates to mental health — and this is a major source of criticism (Groppe, M. 2013). The potential gap between state data collection and federal data storage results from the fact that states, not the federal government, adjudicate mental health in instances of both civil and criminal proceedings. For instance, civil commitment and guardianship proceedings are adjudicated by the state as well as criminal proceedings where the defendant is ruled mentally unfit to stand trial or not guilty for reason of insanity. Thus, adjudications regarding mental health take place in state courts, and that records do not flow automatically into NICS. While some states have passed statutes requiring participation, the first states to actually report mental health records in significant numbers began doing so in 2002. By 2015, all but a handful of states were reporting adjudicated mental health names in earnest.

\section{Firearms, Violence and Mental Health}

As is discussed below, empirical and theoretical work suggests that NICS participation might affect suicides. There is, however, less a priori reason to think NICS participation might affect homicides. It is the tendency immediately after a mass shooting to examine the mental health of the shooter, the origin of the weapon(s) and the failure of the background check (if one was performed). However, the daily reality of gun-related homicides in the U.S. is that the vast majority of firearms used to commit crimes were not obtained through traditional channels of a commercial sale (Cook, P. J., J. Ludwig and A. M. Samaha 2009) and thus would not even be subject to a background check. Even in states that require universal background checks, 
enforcement remains a serious issue (Castillo-Carniglia, A., R. M. C. Kagawa, D. W. Webster, J. S. Vernick, M. Cerdá and G. J. Wintemute 2017). So while many are hopeful that legislation regulating the sale of firearms will reduce flow of firearms and the incidence of homicide, there is strong reason to doubt the efficacy of such regulation given the strength of the secondary market and the vast existing stock of firearms in U.S.

Unlike gun-related homicides, the vast majority of guns used in suicides were subject to background checks, and in many cases, were recent purchases (Edwards, G., E. Nesson, J. Robinson and F. Vars 2017). Though not the only indicator of poor mental health, state suicide rates are generally considered a good measure of the mental healthiness of a state and an extreme outcome of mental health illness (Edwards, G. 2013, Edwards, G. 2016, Marcotte, D. E. and S. Markowitz 2011). While much about suicide remains unknown, there is some evidence to suggest that a suicide attempt represents, for many, a singular event that if avoided will never be repeated (Cox, G., C. Owens, J. Robinson, A. Nicholas, A. Lockley, M. Williamson, Y. T. D. Cheung and J. Pirkis 2013). The unfortunate reality is, however, that while most suicide attempts are not fatal, firearm suicide attempts are highly fatal-around $85 \%$ of firearm suicides result in death compared to $9 \%$ for all other types of suicide (Miller, M., D. Azrael and C. Barber 2012). Because of this, a substantial body of suicide research has found that increases in gun availability leads to increases in gun-related suicides. Given that most of those who survive near fatal suicide attempts end up dying for reasons other than suicide (Cox, G., C. Owens, J.

Robinson, A. Nicholas, A. Lockley, M. Williamson, Y. Cheung and J. Pirkis 2013), it is no surprise that suicides attempts can be avoided entirely if suicide ideation is disrupted (Clarke, R. V. and P. Mayhew 1988, Edwards, G., E. Nesson, J. Robinson and F. Vars 2017). Since firearmrelated suicide attempts are so commonly fatal, it is thus theoretically and practically possible 
that efforts to distance those who may be most at risk of committing suicide from firearms, such as mental health reporting in NICS, may raise the cost of acquiring a firearm just enough to derail suicide ideation or at very least divert to another, less fatal, method of suicide.

While much evidence exists of the relationship between firearm availability and suicides, (Anestis, M. D. and J. C. Anestis 2015, Miller, M., S. J. Lippmann, D. Azrael and D. Hemenway 2007), much less is known about the efficacy of public policies, like background checks, aimed to remove firearms from potentially dangerous individuals. A few studies have looked at state laws mandating mental health reporting and violent outcomes with mixed results (Kleck, G. and E. B. Patterson 1993, Rodríguez Andrés, A. and K. Hempstead 2011, Sen, B. and A. Panjamapirom 2012, Swanson, J. W., E. E. McGinty, S. Fazel and V. M. Mays 2015). These prior studies do not examine actual implementation of these policies on the ground, effectively assuming perfect implementation. We present some evidence, and other research suggests, that implementation is inconsistent at best. (Castillo-Carniglia, A., R. M. C. Kagawa, D. W. Webster, J. S. Vernick, M. Cerdá and G. J. Wintemute 2017, Webster, D. W. and G. J. Wintemute 2015).

One study examined empirically the impact of mental health reporting to NICS on a single state, Connecticut, and focused only on violent crimes (Swanson, J. W., M. A. Norko, H.J. Lin, K. Alanis-Hirsch, L. K. Frisman, M. V. Baranoski, M. M. Easter, A. G. Robertson, M. S. Swartz and R. J. Bonnie 2017). The likelihood of violent crime among those disqualified from a firearm purchase for mental health reasons was significantly lower after NICS reporting began. This study did not examine suicides which the researchers conceded was the "elephant in the room." 
We further the work of the Connecticut study by examining the impact of NICS mental health reporting on both homicide and suicide using panel data regression techniques over 15 years (2001-2015) in all 50 states and the District of Columbia. In place of laws dictating implementation, we are able to calculate the actual year participation began based on the number of names reported. This serves as an advantage in two ways. First, the discrepancies between the stated law and reality are, in many cases, significant. As an example, the 2005 Bureau of Justice Statistics "Survey of State Procedures Related to Firearm Sales" reported that 22 states had laws dictating some sort of adjudicated mental health name participation into NICS (Service, R. J. I. 2005). Data provided by the FBI on the actual number of names in NICS by state suggests that in 2005 only thirteen states actually had any names in the mental health database, and eight of those states had less than twenty names. ${ }^{1}$ Second, a number of states began reporting independent of any statutory nudge. ${ }^{2}$ Consequently, just evaluating the state laws that require reporting would misclassify the states that report without a formal statute requiring participation.

\section{Data}

All four of the outcome variables - firearm-related suicides, non-firearm related suicides, firearm-related homicides, non-firearm related homicides—were collected and obtained through the Centers for Disease Control's (CDC) WISQARS mortality database. Using information collected from death certificates, the CDC collects and reports annual mortality data.

As discussed in the Methods sections, the empirical strategy uses a form of multiple regression analysis, and, in addition to the indicator variable of when a state began NICS

\footnotetext{
${ }^{1}$ As another example, that same document cites Arizona as having a law that required mental health reporting. Arizona did not start reporting mental health names until 2007.

${ }^{2}$ North Carolina is an example of a state that in 2005 had no formal law requiring mental health reporting but had names in the database.
} 
reporting, we include a host of covariates aimed to control for other factors that may be influencing homicides and suicides. Those covariates include the accidental poisoning death rate, the proportion of state population that is male and between 45 and 64 , the proportion of the state that is African American, the accidental firearm death rate, the unemployment rate, and ethanol consumption (Edwards, G., E. Nesson, J. Robinson and F. Vars 2017). In addition to these controls, our model takes advantage of state and year fixed effects. All of these variables are summarized in Table 1.

The independent variable of interest is an indicator variable that equals one in each year a state reported adjudicated mental health names to NICS. The count of names reported by state by year to NICS was gathered from multiple years of FBI NICS Operations reports and from data obtained through Freedom of Information Act (FOIA) requests. ${ }^{3}$ Since we know the number of names added each year by each state, we are mostly able to identify the year in which a state began participation. ${ }^{4}$ At the heart of our identification is the exogeneity of the uptake in NICS participation. We run a variety of tests to address the validity of this assumption discussed in the Methods section. It is important to note however that while NICS participation

\footnotetext{
${ }^{3}$ This data is on file with the authors.

${ }^{4}$ In coding the uptake of NICS participation, we face two primary challenges. First, particularly after 2008 in our dataset, the data available is not always reported at the start or end of a calendar year. For instance, if we only have data for a state at March of 2007 and June of 2008, and we know participation began sometime between those two dates (based on the change of names added), it is not clear precisely when participation began. To keep our estimates conservative, in that instance, we assume that the state began participating in 2007. Second, it is the case for a non-trivial portion of the participating states to report only 1 or 2 names, total, for an entire year. In cases like these, we don't code the state as "participating" until the number of names reported by a state reached a critical mass which we define to be 10 names per 100,000 of the population - though are results are insensitive to other thresholds. As an example, CA reported exactly 1 name in 2002, added ten more names in 2004, added another ten names in 2006, and finally added 200,000 names in 2007. While technically a single name was reported in 2002, in practical terms, CA didn't start participating in earnest until 2007 and we code it as such.
} 
is likely exogenous to trends in gun homicides and suicides, NICS participation occurred through a non-random process for many states.

In the wake of the mass shooting at Virginia Tech in 2007, congress passed the NICS Improvement Amendment Act of 2007. ${ }^{5}$ The purpose was to encourage states to participate in NICS, as the shooter in the Virginia Tech shooting had been adjudicated mentally ill but his name had not been added to NICS. As part of that bill, federal grant money was set aside to offer incentive for individual states to upgrade infrastructure, technology and encourage participation. Between 2009 and 2015, a handful of states successfully applied for and received federal grant money to improve their NICS system. Clearly, this federal grant money is correlated with NICS participation. If it is also correlated with our firearm outcomes, not accounting for the acquisition of federal funds to improve NICS participation would introduce bias into the model. To address the potential for omitted variable bias, we control for the amount of federal grant money received by state by year in each regression and rely on the remaining variation in the timing of initial NICS reporting to estimate the effect of NICS mental health reporting on firearm-related outcomes. As is discussed in the Model Validity section, however, it could also be the case that federal NICS funding to states could be a proxy for an underlying legislative attitude toward firearms.

\section{Methods}

Given that different states began reporting to NICS at different times, we are able to exploit this variation in the timing of NICS participation using a difference-in-differences (DD) approach. Formally, we estimate the following regression equation:

\footnotetext{
${ }^{5}$ See https://www.bjs.gov/index.cfm?ty=tp\&tid=49 for a summary of this Act.
} 


$$
\text { (1) } \quad \ln \left(s_{i t}\right)=\alpha+\beta W_{i t}+\theta \mathrm{X}_{i t}+\gamma_{t}+\tau_{i}+\varepsilon_{i t}
$$

where $\ln \left(s_{i t}\right)$ is the natural $\log$ of the firearm homicide/suicide rate or the non-firearm homicide/suicide rate in state $i$ at time $t, X$ is a vector of controls outlined in the Data section, $\gamma$ is a set of year indicator variables, $\tau$ is the set of state indicator variables, and $W_{i t}$ is the independent variable of interest, a dummy variable flagging the states by year that are participating in NICS by reporting mental health names to NICS. That is, based on the actual names reported, once a state begins reporting names in earnest, $W_{i t}$ takes on the value of one. The interpretation of $\beta$ is the marginal effect of participation on our outcomes in percentage terms. This framework essentially allows us to estimate the change in homicide and suicide rates before and after NICS participation began and compare it to the same change in all the control states that did not change at the same time.

\section{Model Validity}

In order for these regressions to produce reliable results, there are multiple assumptions and considerations. One critical assumption of DD regression analysis is commonly referred to as the pretreatment parallel trends assumption (Angrist, J. and J. Pischke 2008). In order for our pseudo-treatment and control framework to produce valid results, it must be the case that each group, the treatment and control states, has a similar trend in the outcome prior to treatment. Stated another way, we need to confirm that states that entered the NICS system were experiencing the same trends in homicide and suicide rates as the states that did not enter NICS (and thus serve as the control group). To test this formally, we slightly alter the specification in equation (1) to include dummy variables for each of the years leading up to NICS participation where the last full year prior to participation is omitted and serves as an alternative comparison group. If the pretreatment trends are different between the treatment and control groups, these 
dummy variables would be individually statistically significant and should jointly be statistically different from zero. The associated $\mathrm{p}$-value for this test is reported in Tables 2 and 3 . These dummy variables never approach statistical significance which suggests some validity to the pretreatment parallel trends assumption.

An additional consideration in DD regressions is the treatment of the standard errors (Bertrand, M., E. Duflo and S. Mullainathan 2004). In each model, we cluster the standard errors at the state level. Another, broader issue, is the direction of causality between homicides and suicides and the number of mental health names reported to NICS. It is not clear, a priori, whether the actual number of mental health names being reported is driving homicide and suicide rates or whether homicide and suicide rates are driving NICS reporting. It is possible that an underlying and unobserved endogenous force drives both the number of mental health names contained in NICS and suicides. If true, NICS records would be endogenous to the regression and bias the results. For these reasons, our identification comes not off the variation in the actual numbers of names in the database per state per year, but rather off of the year the state began reporting mental health names to NICS. Our empirical strategy is akin to state panel DD regressions that evaluate state level policy (Edwards, G. 2016), but in place of identifying off of the idiosyncratic variation in laws, we identify off of the idiosyncratic variation in participation uptake which anecdotal evidence suggests is more likely to be driven by high profile mass shootings, specifically the shooting at Virginia Tech, and not trends in homicides or suicides (Rosenberg, J., S. Rosenberg, S. Ellefson and P. Corrigan 2014).

Nonetheless, we are able to address direction of causality in two ways. First, if there is an unobserved factor correlated with both homicide and suicide rates and NICS reporting rates, we would expect lagged homicide and suicide rates to serve as a good predictor of the start of 
NICS participation. While these results are available upon request, all such tests generate no evidence that a previous year's suicide or homicide rate predicts a state's participation in the NICS system.

As was mentioned previously, while we believe that NICS participation is exogenous to our outcomes of interest, we do know that for many states NICS participation is endogenous to the Virginia Tech mass shooting and/or the federal funding that came in response to that shooting. So while the horrific events surrounding the Virginia Tech shooting were random, the systematic state response may not have been. For instance, if a set of state legislators had an underlying firearm agenda, their response to the random event of the Virginia Tech shooting might be endogenous in our model. Said another way, receiving federal grant money to participate in NICS might just be a proxy for some sort of policy endogeneity. If true though, this policy endogeneity only soils our model if it's endogenous to firearm suicides and firearm homicides. Fortunately, we can directly test if firearm suicide and homicide trends drove the gaining of federal grant funds.

Similar to the method mentioned previously, we attempt to predict the probability of getting grant money and separately the amount of money received using lagged firearm homicide and suicide rates. The idea being that if state legislators have some sort of policy endogenous attitude towards firearms as measured by the federal grant money received, and those attitudes are based on the actual trends in firearm homicides and suicides, it should be that firearm homicide and suicide trends in the years leading into the year the grant money is received should be a significant predictor of the probability of getting funds or the amount of funds received. In no case do we find any evidence that either of our lagged outcome variables of interest predict in any way the probability of getting any money or the amount of money received. Simply put, if a 
state got grant money to improve their NICS system, it wasn't the result of some sort of reaction to suicide or homicide rates at that time. This result, coupled with the parallel trends test seems to suggest the NICS participation was exogenous to our outcome variables.

\section{Results}

The results for homicides are reported in Table 2 and for suicides in Table 3. In both tables, each column represents a unique regression. In each table, columns (1) and (4) include no controls, and columns (3) and (6) include the pretreated parallel trends assumption test and the associated $p$ values. A state's participation in the NICS database is not associated with any statistically significant change in homicide rates, either firearm or non-firearm related (Table 2). In contrast, NICS mental health reporting is associated with a 3.3-4.3\% decrease in firearmrelated suicides (Table 3$){ }^{6}$

There is concern that preventing a firearm purchase by potential victims will just lead to other methods of suicide attempts (Briggs, J. T. and A. Tabarrok 2014). At the onset, there is reason to doubt this so-called substitution effect because, as mentioned previously, many of those who attempt suicide and survive do not ever return to attempt and end up dying for reasons other than suicide. Even if there were substitution from a firearm suicide to any other method of suicide, that would still be preferred since suicide attempts are far more lethal than most other methods and thus would not likely be visible from the data since we our measure only includes lethal suicide attempts (Miller, M., S. J. Lippmann, D. Azrael and D. Hemenway 2007). Thus, if firearm access regulation were diverting those considering suicide to other lethal methods of suicide, we would expect to see that NICS participation would increase non-firearm suicides. In

\footnotetext{
${ }^{6}$ As mentioned previously, there is reason to believe that the actual number of names added per year is endogenous and thus we do not include it in any of our specifications.
} 
Table 3, we find no evidence of any relationship between non-firearm suicides and NICS reporting, and thus no evidence of a substitution effect. We want to be careful to point out that this does not necessarily mean that the individual discouraged from purchasing a firearm by NICS participation does not attempt suicide by another method, just not another fatal method.

Our main results assume that the effect of participation is uniform across each year postparticipation. There is reason to suspect, however, that the effect of a state's contribution to NICS might vary as the years pass. To address this, we report the results of an event study style regression in Figure 1. The specification of this figure is very similar to that of column (3) in Table 3, including controls, except that in place of one dummy variable that encompasses all treated years, that variable is split into a dynamic effect by year set of dummy variables including the pre-treated dummy variables that address the parallel trends assumption. In Figure 1 , the vertical axis measures the magnitude of the coefficient, the horizontal axis measures the timing before and after participation begins where the last full year prior to participation is held out, and the bands represent $90 \%$ confidence intervals. To allow for more precise estimates, each dummy variable spans two years in a manner similar to Wolfers, J. (2006). As expected, all three dummy variables capturing the time prior to participation are not individually significant. Interestingly, however, we notice in Figure 1 that the longer it has been since a state started participating in NICS, the stronger the deterrent effect seems to be.

As an additional robustness check, we examine the interactive effect of gun availability and NICS participation on suicide. Theoretically, any policy aimed to decrease access to firearms would be the least potent in states where guns are readily present and available. That is, the impact of a restriction on gun purchases should be greatest in states where individuals do not already own guns or have easy access to guns from family, friends, or private sellers. To 
estimate this formally, we take the baseline specification in equation (1) and interact the main policy variable by the availability of guns in a state where states are divided into four sub-groups based on gun availability measured in terms of the average number of per capita background checks performed by state. The results, presented in Figure 2, suggest that NICS participation has the most potent impact in states that have the fewest guns circulating through society (the bottom two quartiles). That is, NICS participation seems to deter the most suicides in states where guns are not otherwise readily accessible.

\section{Discussion}

In the current social and political climate, finding common ground on firearm regulation may seem impossible, but nearly everyone favors restricting firearm access by those who are deemed mentally unfit. Perhaps surprisingly, the rationale usually given for this restrictionreducing fatal harm to others-is not supported by our data. We do, however, find that when states report mental health records, those states experience a roughly $4 \%$ reduction in firearmrelated suicides. This translates into roughly 750 fewer suicides yearly. This effect seems to strengthen over time and is largest in states with relatively low access to firearms. Suicide remains one of the foremost public health problems, and our results suggest that reporting mental health records to NICS is an effective way to prevent some suicides.

Conversely, while there may be reasons to think (or hope) that mental health restrictions would reduce homicides, especially since mental illness is often cited as a cause of many horrific mass shootings, we find no statistically significant association between homicide and NICS reporting of persons "who ha[ve] been adjudicated as a mental defective or who ha[ve] been committed to a mental institution." Sensationalized reporting of large-scale mass shootings does 
not reflect the thousands of homicides that do not grab headlines. Given the debate that is taking place not just in legislatures but also in courtrooms, it is important to recognize the limitations of a gun restriction is essential in crafting policy.

The Supreme Court in 2008 held for the first time that the Second Amendment protects an individual's right to bear arms. ${ }^{7}$ At the same time, the Court stated that its holding did not call into question the mental health restriction examined in this paper. Lower courts, however, apply a more nuanced approach that examines how well the restriction actually reduces suicide. ${ }^{8}$ Until now, courts have been forced to rely on indirect evidence, speculation, and inference (Vars, F. and A. Young 2013). The present study tests directly the key questions. Reasonable jurists may still disagree about the constitutionality of the mental health restriction, but their decisions will rest on firmer ground.

${ }^{7}$ District of Columbia v. Heller, 554 U.S. 570, 576 (2008)

${ }^{8}$ Tyler v. Hillsdale County Sheriff's Department, 837 F.3d 678 (6th Cir. 2016) 


\section{References}

: "United States Code."

ANESTIS, M. D., AND J. C. ANESTIS (2015): "Suicide Rates and State Laws Regulating Access and Exposure to Handguns," Am J Public Health, 105, 2049-58.

ANGRIST, J., AND J. PISCHKE (2008): Mostly Harmless Econometrics: An Empiricist's Companion Princeton, NJ: Princeton University.

Bertrand, M., E. Duflo, AND S. Mullainathan (2004): "How Much Should We Trust Differences-inDifferences Estimates?," The Quarterly Journal of Economics, 119, 249-275.

BRIGGS, J. T., AND A. TABARROK (2014): "Firearms and Suicides in Us States," International Review of Law and Economics, 37, 180-188.

Castillo-Carniglia, A., R. M. C. Kagawa, D. W. Webster, J. S. Vernick, M. Cerdá, and G. J. Wintemute (2017): "Comprehensive Background Check Policy and Firearm Background Checks in Three Us States," Injury Prevention.

Center, P. R. (2017): "Among Republican Gun Owners, Nra Members Have a Distinct Set of Policy Views."

ClARKe, R. V., AND P. MAYHeW (1988): "The British Gas Suicide Story and Its Criminological Implications," Crime and Justice, 10, 79-116.

COOK, P. J., J. LUDWIG, AND A. M. SAMAHA (2009): "Gun Control after Heller: Threats and Sideshows from a Social Welfare Perspective," UCLA Law Review, 56.

Cox, G., C. OWens, J. Robinson, A. NiCholas, A. Lockley, M. Williamson, Y. Cheung, AND J. PIRKIS (2013): "Interventions to Reduce Suicides at Suicide Hotspots: A Systematic Review," BMC Public Health, 13, 1-12.

Cox, G., C. OWens, J. Robinson, A. Nicholas, A. Lockley, M. Williamson, Y. T. D. Cheung, and J. PiRkis (2013): "Interventions to Reduce Suicides at Suicide Hotspots: A Systematic Review," BMC Public Health, 13, 214.

EdWARDS, G. (2013): "Tarasoff, Duty to Warn Laws, and Suicide," International Review of Law and Economics, 34, 1-8.

EdWARDS, G. (2016): "State Right to Refuse Medication Laws and Procedures: Impact on Homicide and Suicide," J Ment Health Policy Econ, 19, 141-54.

EdWARDS, G., E. NESSON, J. Robinson, AND F. VARS (2017): "Looking Down the Barrel of a Loaded Gun: The Effect of Mandatory Handgun Purchase Delays on Homicide and Suicide," The Economic Journal, forthcoming.

GROPPE, M. (2013): "Checking Gun Buyers for Mental Illness Hinges on States."

KLECK, G., AND E. B. PATTERSON (1993): "The Impact of Gun Control and Gun Ownership Levels on Violence Rates," Journal of Quantitative Criminology, 9, 249-287.

MARCOTTE, D. E., AND S. MARKOWITZ (2011): "A Cure for Crime? Psycho-Pharmaceuticals and Crime Trends," Journal of Policy Analysis and Management, 30, 29-56.

Miller, M., D. AzRAEL, AND C. BARBER (2012): "Suicide Mortality in the United States: The Importance of Attending to Method in Understanding Population-Level Disparities in the Burden of Suicide," Annual Review of Public Health, 33, 393-408.

Miller, M., S. J. LipPMANN, D. AzRAel, AND D. Hemenway (2007): "Household Firearm Ownership and Rates of Suicide across the 50 United States," J Trauma, 62, 1029-34; discussion 1034-5.

NRA (2016): "Wayne Lapierre | the Truth About Background Checks."

Rodríguez ANDRÉs, A., AND K. HEMPSTEAD (2011): "Gun Control and Suicide: The Impact of State Firearm Regulations in the United States, 1995-2004," Health Policy, 101, 95-103. 
Rosenberg, J., S. Rosenberg, S. Ellefson, and P. Corrigan (2014): "Public Mental Health Stigma and Mass Shootings," SAJ Forensic Sci, 1.

SEN, B., AND A. PANJAMAPIROM (2012): "State Background Checks for Gun Purchase and Firearm Deaths: An Exploratory Study," Preventive Medicine, 55, 346-350.

SERVICE, R. J. I. (2005): "Survey of State Procedures Related to Firearm Sales."

SWANSON, J. W., E. E. McGinty, S. FAZEL, AND V. M. MAYs (2015): "Mental Illness and Reduction of Gun Violence and Suicide: Bringing Epidemiologic Research to Policy," Annals of Epidemiology, 25, 366-376.

SWANson, J. W., M. A. Norko, H.-J. Lin, K. Alanis-Hirsch, L. K. Frisman, M. V. Baranoski, M. M. Easter, A. G. ROBERTSON, M. S. SWARTZ, AND R. J. BONNIE (2017): "Implementation and Effectiveness of Connecticut's Risk-Based Gun Removal Law: Does It Prevent Suicides the Second Generation of Second Amendment Law \& Policy," Law and Contemporary Problems, 80, 179-208.

VARS, F., AND A. Young (2013): "Do the Mentally III Have a Right to Bear Arms?," Wake Forest L Rev, 48, 124.

Webster, D. W., AND G. J. WintemUte (2015): "Effects of Policies Designed to Keep Firearms from High-Risk Individuals," Annual Review of Public Health, 36, 21-37.

Wolfers, J. (2006): "Did Unilateral Divorce Laws Raise Divorce Rates? A Reconciliation and New Results," American Economic Review, 96, 1802-1820. 


\section{Tables}

Table 1

\begin{tabular}{lcc} 
Variable & Mean & Std. Dev. \\
\hline Firearm Suicide Rate & 7.272 & 3.131 \\
Non-Firearm Suicide Rate & 6.233 & 1.656 \\
Homicide Firearm Rate & 3.655 & 3.124 \\
Non-Firearm Homicide Rate & 1.847 & 1.051 \\
NICS Participation & 0.374 & 0.484 \\
NICS Reporting Rate per 100,000 & 206.115 & 597.272 \\
Poisoning Death Rate & 9.963 & 5.090 \\
Real Mental Expenditures & 94.664 & 59.398 \\
Male 45 to 64 Population Rate & 32.157 & 2.161 \\
Proportion African American & 0.078 & 0.114 \\
Accidental Firearm Death Rate & 0.364 & 0.378 \\
Unemployment Rate & 6.073 & 2.016 \\
Ethanol Consumption (1,000s of gallons) & 11,000 & 12,200 \\
\hline
\end{tabular}


Table 2: NICS Participation on Homicides

1. Firearm Homicides

2. Non Firearm Homicides

\begin{tabular}{cccc|ccc}
\hline & $(1)$ & $(2)$ & $(3)$ & $(4)$ & $(5)$ & $(6)$ \\
NICS MH Reporting & 0.033 & 0.073 & 0.049 & -0.041 & 0.000 & 0.014 \\
& $(0.049)$ & $(0.045)$ & $(0.046)$ & $(0.034)$ & $(0.029)$ & $(0.036)$ \\
\cline { 2 - 7 } Controls & & $\mathrm{X}$ & $\mathrm{X}$ & & $\mathrm{X}$ & $\mathrm{X}$ \\
Parallel Trends Test P Value &. &. & 0.576 &. &. & 0.979 \\
Sample Size & 761 & 761 & 761 & 758 & 758 & 758 \\
R Squared & 0.899 & 0.907 & 0.907 & 0.712 & 0.729 & 0.729 \\
\hline
\end{tabular}

Notes: Each column represents a unique regression. Columns (2), (3), (5), and (6) include controls highlighted in the data section and columns (3) and (6) include dummy variables to test for parallel trends pretreatment. Standard errors, in parentheses, are clustered at the state level to address autocorrelation in the errors. ${ }^{\wedge} \mathrm{p}<0.10 \dagger \mathrm{p}<0.05 \ddagger \mathrm{p}<0.01$ 
Table 3: NICS Participation on Suicides

1. Firearm Suicides

2. Non Firearm Suicides

\begin{tabular}{cccc|ccc}
\hline & $(1)$ & $(2)$ & $(3)$ & $(4)$ & $(5)$ & $(6)$ \\
NICS MH Reporting & $-0.043 \dagger$ & $-0.036 \dagger$ & $-0.043 \dagger$ & -0.015 & -0.017 & -0.011 \\
& $(0.018)$ & $(0.017)$ & $(0.020)$ & $(0.015)$ & $(0.016)$ & $(0.016)$ \\
\cline { 2 - 7 } Controls & & $\mathrm{X}$ & $\mathrm{X}$ & & $\mathrm{X}$ & $\mathrm{X}$ \\
Parallel Trends Test P Value &. &. & 0.688 &. &. & 0.921 \\
Sample Size & 765 & 765 & 765 & 765 & 765 & 765 \\
R Squared & 0.961 & 0.964 & 0.964 & 0.866 & 0.870 & 0.871 \\
\hline
\end{tabular}

Notes: Each column represents a unique regression. Even number columns include controls highlighted in the data section and columns (2), (3), (7) and (8) include dummy variables to test for parallel trends pretreatment. Standard errors, in parentheses, are clustered at the state level to address autocorrelation in the errors. ${ }^{\wedge} \mathrm{p}<0.10 \dagger \mathrm{p}<0.05 \$ \mathrm{p}<0.01$ 
Figures

Figure 1: Effect of NICS Participation on Firearm Suicide by Centered Years

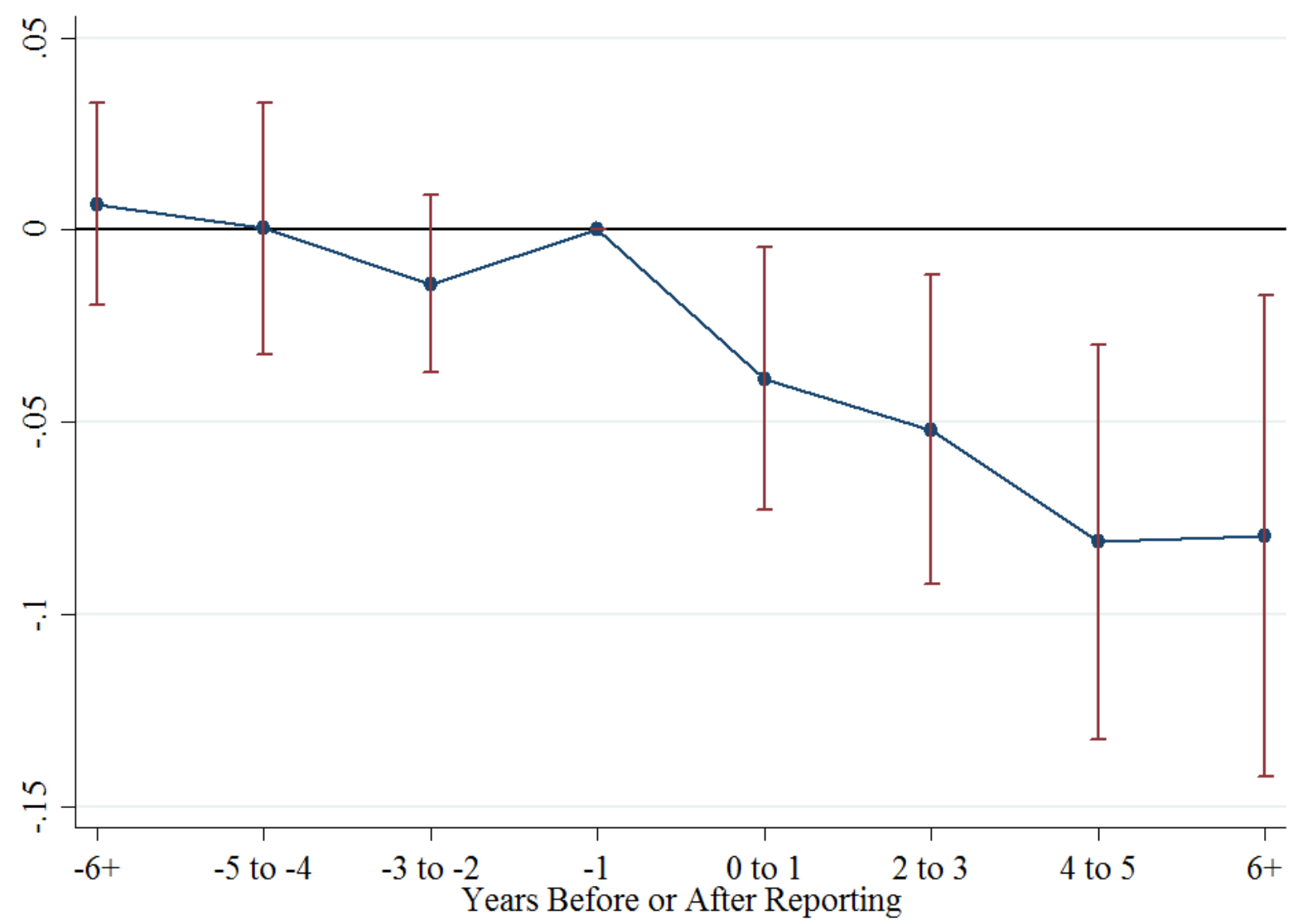


Figure 2. Effect of NICS Participation on Firearm Suicides by Gun Availability

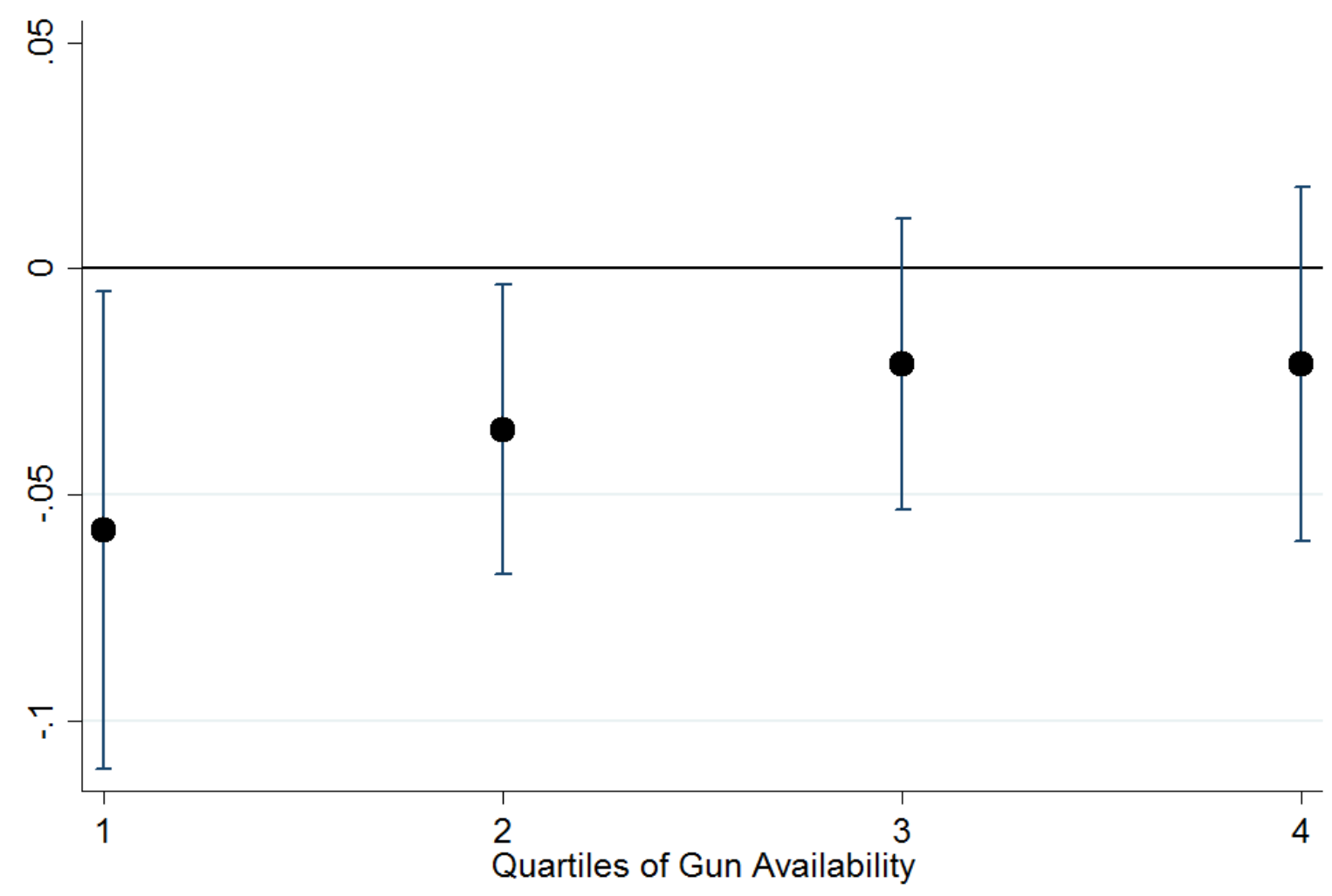

